\title{
City and Environment
}

\author{
Pieter Glasbergen
}

Published online: 22 October 2008

(C) The Author(s) 2008. This article is published with open access at Springerlink.com

Christopher G. Boone and Ali Modarres, Temple University Press, Philadelphia, 2006, 221 pp, ISBN:1592132847

This book takes a social-ecological approach to the study of the sustainability of cities. The approach aims to connect the biological and geophysical processes studied by ecologists with knowledge about human behavior as studied by social scientists. The book also aims to help in the search for pathways that can turn cities into ecologically sustainable places. Most of the chapters address cities in the developing and developed world from both a historical and a comparative perspective.

The first chapter presents a historical description of urban morphologies. It is concluded that mobility, purpose, and organization remain the forces that shape our cities, though these concepts are not systematically applied in the analyses of morphological change.

Chapter 2 studies cities as arenas in which the dynamics of population are played out. The chapter covers a wide range of topics: e.g., the consumption of resources, with an interesting analysis of the correlation between population growth, urbanization, and energy consumption; population and health; and the politics of population control, with a case study of India. This chapter makes it clear that population growth, consumption, and the environment are intricately connected. Sustainability is needed to help realize a balanced approach.

Chapter 3 is dedicated to agriculture. It discusses the irony that farms feed cities while urban growth threatens agricultural land. The ecological footprint is one of many interesting topics discussed.

Chapter 4 is focused on urban infrastructure. It discusses roads and transit, watering and draining, and waste removal, the environmental consequences of all of these, and some green alternatives.

Chapter 5 connects the issue of health with the environmental justice movement. The analysis of health in cities is complicated by the great disparities within cities and rural areas. The topic is taken up by the healthy city concept, though this concept lacks

P. Glasbergen $(\bowtie)$

Copernicus Institute for Sustainable Development and Innovation, Utrecht University,

P.O. Box 80.115, Utrecht, The Netherlands

e-mail: p.glasbergen@geo.uu.nl 
operational practices, and by the environmental justice movement, where more attention is given to disamenities than amenities. Nonetheless, the vitality of the movement suggests a strong mobilizing force.

The final chapter tackles the issue of green spaces in cities. Again, many aspects are considered: among others, parks in the city, garden cities, but also smart cities and new urbanism.

This book is not an easy read, and not only because of its encyclopedic character. The difficulty lies first and foremost in its underlying concept. The book lacks a coherent analytical perspective. For instance, the approach taken is not explicated in a research design with guiding questions that are systematically answered. The subsequent chapters also lack central questions and therefore internal coherence, and none of them have summaries. This lack of coherence might have been overcome by providing an argumentation of the topics covered and their relationships, but that opportunity was also missed. As a consequence, the reader regularly wonders why he is reading the part he is reading. The promised pathways to sustainable cities, if discussed at all, are not presented systematically; one seeks them in vain, for example in a final chapter.

The book is best seen as a compilation of essays around topics somehow related to city and environment. Though rich in information on specific themes, there are too many topics discussed in an unsystematic way to make the book a convincing whole. Nonetheless, the individual chapters may be interesting to students of a specific topic.

Open Access This article is distributed under the terms of the Creative Commons Attribution Noncommercial License which permits any noncommercial use, distribution, and reproduction in any medium, provided the original author(s) and source are credited. 